\title{
DEVELOPMENT OF THE IMPROVED METHODS OF FIGHT AGAINST DISTRIBUTION OF SMOKE ON SHIP WITH SYSTEMS OF JET WATER-GAS EJECTORS
}

\author{
Volodymyr Blintsov \\ Admiral Makarov National University of Shipbuilding \\ 9 Heroiv Ukraine ave., Mykolaiv, Ukraine, 54025 \\ volodymyr.blintsov@nuos.edu.ua \\ Sergiy Hrynchak \\ Department of Shipbuilding \\ Naval Forces of AF of Ukraine \\ 1 Shtabna str., Odessa, Ukraine, 65012 \\ grinserg69@gmail.com
}

\begin{abstract}
The ways of improving the design of ship openings with the implementation of a method for reducing the intensity of the exit of flue gases through an opening (doors, hatches) of the emergency premise of the ship are considered. The output of flue gases from the emergency premise is proposed to be controlled by the control of gas-air currents with the help of a system of jet water-gas ejectors. Ejectors are equipped with devices for collecting flue gases from the emergency premise of the ship and the collectors of the output of the vapor-gas mixture back to the emergency premise.

In case of fire, in the shortest possible time, a high temperature rises in the area of exit from the emergency premise of the ship and a large amount of smoke spreads along the corridors and premises of the ship. These factors require immediate sealing of the emergency premise, which limits the operational access of emergency teams to combat fire.

The considered air suppression methods in the ship's aperture and devices for their implementation contribute to screening of heat energy and localization of flue gases in the emergency premise without its sealing to ensure prompt access of emergency teams.

Keywords: jet water-gas ejector, ship openings, design methods, operational access.
\end{abstract}

\section{Introduction}

Ship's openings on the ship are designed for communication between adjacent premises or for access to the open space of the deck. Closure of the openings is provided by doors and hatches, which are installed in the ship's protective fences (partitions, decks). Specificity of the use of ship's openings puts forward a number of requirements for them, concerning the selection of materials for their manufacture, their reliability, strength, quality.

At present, the design of the openings is carried out according to the methods providing for the fulfillment of the requirements for fire safety of the ship [1].

One of the most important requirements for ship openings (their closure) is their fire resistance and the ability to respond to emergency situations, namely the closing speed and the quality of localization of the consequences of fires [2]. Concerning ship fires, this amounts to sealing the emergency premise [3-5]. However, the accumulated experience in combating ship fires shows that during a period between the onset of a fire (ignition and the onset of formation of combustion products) and the moment of sealing, a significant part of the high-temperature flue gases through the openings go beyond the emergency premise. At the same time, the sealing of this space excludes the operational access of fire brigades.

From the foregoing it follows that in a complex of tasks of providing ship fire protection, an important task is maintaining of openings in the open state while simultaneously preventing gas exchange with adjacent premises. Therefore, the applied scientific and technical task of developing methods for designing ship openings with the suitability of gas exchange in case of fire without their closing is relevant. 


\section{Literature review}

Attempts to protect ship's openings from smoke and high temperatures have been done repeatedly. Thus, on ships of relatively large displacement [6-8], the ladders in the energy compartments (EC) of ships to equip dangerous consequences of the fire are equipped with stationary systems of irrigation of the space at the ladders from the lower sites of the EC. This allows to protect personnel, evacuated, at least from the heat impact. The main disadvantage of the system of irrigation of ship's ladders is the possibility of spreading flue gases through an open aperture beyond the emergency EC on other premises of the ship.

Another known means of reducing the intensity of smoke and toxic gases outside the emergency premise is the rotary curtains, which are irrigated with seawater [9]. Such devices have in their composition two parallel П-shaped collectors with centrifugal-jet sprayers, which are located parallel to the ship's aperture, one along the perimeter of the opening and the second outer one. Between the collectors on the swivel bars, which can rotate around the longitudinal axis, curtains are fixed that are irrigated when feeding seawater. The disadvantage of this technical solution for ships of small displacement, where small ECs have a large amount of electrical equipment, is the threat of the failure of this equipment as a result of its irrigation.

General issues of fire protection on marine facilities, and in particular on cruise ships and military courts, are discussed in [10-12].

The application of special passive materials, in particular synthetic fibers, to reduce the risk of fire is considered in [13].

Application of systems based on jet gas and water ejection systems (JGWE) can be an effective solution to decrease the intensity of the spread of hazardous fire factors while simultaneously preventing the drawbacks of using open irrigation systems [14].

The aim of the article is improving the design of the fire-fighting system of the ship by applying the system of local air support, formed by the flow of vapor-gas-air mixture directed to the emergency boat compartment, using jet gas-water ejectors.

To achieve the aim, the following tasks must be solved:

- to establish the regularities of the formation of an air curtain at the doors of the projected ship in the control of gas flows in the flow section;

- to formalize processes of formation of an air curtain, at which the output of high-temperature flue gases from the emergency premise of the ship will be reduced without its sealing.

\section{Principles of operation of a jet water gas ejector}

JWGE is a sparkless driver for the flow of working fluid (water). When the working fluid is supplied to the multi-jet nozzle under pressure, there is a discharge on the input part of the housing (elector). Due to the discharge of the gas-air medium, it is squeezed inside the body. After interacting with the droplets of the micronized liquid, the gas-liquid mixture moves from the inlet to the original (separator with the outlet). The interaction of the gas-air mixture with the droplets of the working fluid is based on the processes of heat and mass transfer, as a result of which a purified, moistened and cooled gas-air mixture is formed at the housing outlet. At the same time, the spent working fluid is discharged into the drain opening.

In experimental and theoretical studies, it is established that JWGE is an effective tool for reducing smoke concentration in an emergency premise [15]. Solid soot particles, when interacting with droplets of working fluid, "stick" on the drops and are removed from the premise together with the spent working fluid.

Minor modernization of the exit part of the JWGE series of experimental studies allows to obtain a number of results that allow to propose a new method of fire extinguishing [16]. The method is based on ejecting combustion products from the top of the premise, cooling and moistening of this medium, deposition of large and small aerosols on a highly developed heat and mass exchange surface and the withdrawal of the resulting inert mixture into the lower part of the premise from the periphery to the center. This is achieved by mixing the gas-air environment of the emergency premise, reducing the volume concentration of oxygen, isolating it from the source of combustion and extinguishing the 
fire. Thus, the placement of JWGE on transverse bulkheads makes it possible to realize a method for localizing and extinguishing a fire in a premise with openings without sealing them.

When applying this method, several effects are simultaneously achieved:

- decrease in the temperature in the volume of the emergency premise and the gas-air mixture is introduced into the premise;

- selection of heat from the fire;

- reduction of oxygen concentration in the volume of the emergency premise;

- formation of a gas-air medium cooled with increased moisture content in the volume of the premise;

- low permeability for the radiant component of the heat flux from the source due to the presence of a water spray vapor.

Also, when placing JWGE on transverse bulkheads and during their operation in an emergency premise, the following processes occur [16]: flue gases are intensively withdrawn from the upper part of the premise, the excess pressure is reduced and the flue gas output is reduced through an opening in an adjacent premise; An inert mixture is injected into the lower part of the premise, giving a decrease in the intensity of air sucking from the adjacent premise through an open aperture.

Consequently, this method allows to obtain the effect of "artificial sealing", i. e., a decrease in the gas exchange rate with open apertures. This effect allows to fight fire in the compartment when the bulkheads are open, in particular, unhindered to enter the fire brigade in the compartment.

However, to this day, only the design solutions of JWGE intended for use in the volume (located in the middle) of the emergency premise were considered and investigated.

Disadvantages of the methods of considered design and devices are the following:

- the method of equalization of local static pressures is ineffective for openings located in horizontal floors (decks) of ships and does not exclude the exit of high-temperature flue gases through an open hatch to the premises located above the emergency premise;

- the device is not effective enough to form a retaining stream;

- the complexity of practical implementation, since the design solutions have sufficiently large overall dimensions;

- large overall dimensions make it difficult to install them in the ship's premises, and equipment that ensures operation of the ship as intended.

Thus, it is obvious that the design of JWGEs needs to be improved to be installed in the openings of the premise in order to shield thermal energy and localize flue gases in these premises without their sealing to ensure prompt access of emergency teams.

Moreover, when developing structural solutions and equipping them with ship openings, it is necessary to provide their various applications in both vertical fences (doors) and horizontal floors (hatches).

\section{Theoretical foundations of the functioning of jet water-gas ejectors as sources of local air supply in emergency premises of ships}

Constructive solutions for providing ship openings with the systems of local air supply for the purpose of "artificial" localization of flue gases in these premises (without their sealing) can be realized in the form of stationary smoke protection systems (Fig. 1). The structure and operation of such complexes are considered in detail in [17, 18].

Fig. 1 denotes: 1 - separator; 2 - directing branch pipe; 3 - JWGE body; 4 - multi-jet nozzle; 5 - pipeline of working fluid; 6 - yield of the inert mixture; 7 - motion of the gas phase in the body of the jet water-gas ejector; 8 - directing branch pipe of an entrance part; 9 - air intake; 10 - system for removing spent working fluid; 11 - flue gases; 12 - JWGE; 13 - ship's opening.

To confirm the efficiency of the proposed methods of smoke localization and shielding of the heat flow in the emergency premise area, theoretical studies [17-19] are carried out. The content of these studies stems from the statement that gas exchange is mathematically described by the equation of the material balance of the gas phase for a premise with opening [20]:

$$
\mathrm{V} \frac{\mathrm{d} \rho_{\mathrm{m}}}{\mathrm{d} \tau}=\mathrm{G}_{\mathrm{W}}+\psi-\mathrm{G}_{\mathrm{G}},
$$


where $\mathrm{V} \frac{\mathrm{d} \rho_{\mathrm{m}}}{\mathrm{d} \tau}-$ the change in the mass of the gas over the time interval, $\mathrm{kg} / \mathrm{s} ; G_{\mathrm{W}}, G_{\mathrm{G}}-$ mass flow of air and gaseous combustion products through the opening, $\mathrm{kg} / \mathrm{s} ; \psi-$ the mass combustion rate of the material, $\mathrm{kg} / \mathrm{s}$.

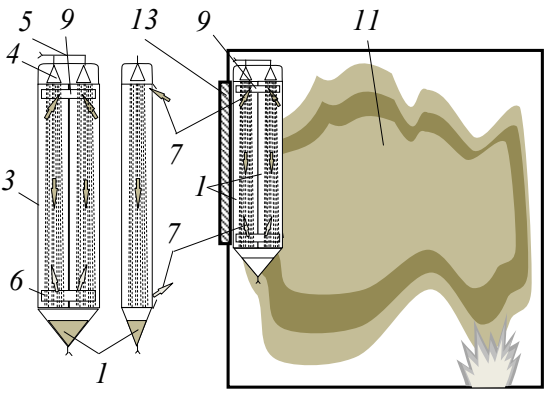

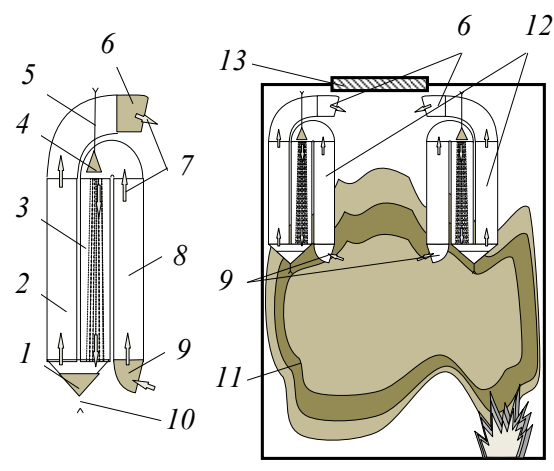

$b$

Fig. 1. Schemes of installation of local air supply systems in the ship openings: $a$ - the device of air supply in the doors; $b$ - the device of air supply in the emergency hatch

The problem of reducing gas exchange through an open aperture during a fire in the first approximation reduces to the search for conditions under which the first and third terms of equation (1) tend to zero. That is, equation (1) can be written in the form:

$$
\mathrm{V} \frac{\mathrm{d} \rho_{\mathrm{m}}}{\mathrm{d} \tau}=\psi
$$

which corresponds to the conditions for the development of fire in the absence of gas exchange with the environment (airtight premise).

During the theoretical studies, simulated zone modeling of the JWGE operation in the openings of the emergency premise is performed, for which the 2D hydrodynamic tasks of the JWGE operation in a semibounded volume are solved and the interband gas exchange equations in the emergency premise are compiled [17, 19].

During the simulation, the development of fire in the ship's premises, isolated from the adjacent premise by metal structures with opening (door - in one version and emergency hatch in the second one), with uneven distribution of the fire load and limited heat and gas exchange with the environment are considered. In the vicinity of the openings, the JWGE is installed to provide shielding:

- flue gases due to their localization in the volume of the emergency premise with simultaneous precipitation;

- radiation of thermal energy due to the processes of heat exchange between the gas phase, eccentricity and dropping flow.

The second task of theoretical studies is determination of the dependence of the distribution mechanism of the velocity fields of the air-gas medium on the cutoff of the opening on the parameters and JWGE operating characteristics, the initial characteristics of the gas-air medium,

It has been established that during the flow of flue gas through the opening, two thirds of the opening is operated to exit the flue gas to an adjacent premise, and one third to the inlet of fresh air [20].

The velocity of the flue gas flow is described by the equation [20]

$$
v=\sqrt{2 g h \frac{\rho_{a}-\rho_{2}}{\rho_{a}}},
$$

where $\rho_{a}$ - density of air at height $\mathrm{h}, \mathrm{kg} / \mathrm{m}^{3}$. 
According to the law of Mendeleev-Clapeyron

$$
\mathrm{p}_{2}=\rho_{2} \mathrm{~T}_{2} \mathrm{R},
$$

where $T_{2}$ - the average temperature, $K ; R$ - the universal gas constant, $R_{m} \approx 300 J /(k g \times K)$.

Then expression (3) can be reduced to the form

$$
v=\sqrt{2 g h \frac{T_{2} P_{a}-T_{a} P_{2}}{T_{2} P_{a}}} .
$$

The volume flow of flue gases and the inflow of air through the opening are described by the equations [20]

$$
\begin{gathered}
Q_{g}=2 / 3 h_{o} b_{o} v=2 / 3 h_{o} b_{o} \sqrt{2 g h_{o} \frac{T_{2} P_{a}-T_{a} P_{2}}{T_{2} P_{a}}}, \\
Q_{i}=1 / 3 h_{o} b_{o} v=1 / 3 h_{o} b_{o} \sqrt{2 g h_{o} \frac{T_{a} P_{4}-T_{4} P_{a}}{T_{a} P_{4}}},
\end{gathered}
$$

where $Q_{g}, Q_{i}$ - the volume flow of flue gases and air inflow through the opening, $\left(\mathrm{m}^{3}\right)$.

But when installing in the opening of the operating JWGE, the process of distribution of flue gas flows from the emergency premise and air from the adjacent one occurs. In the part of the opening that is equipped with JWGE air intakes, the flow will move towards the elector, and in the place at the JWGE outlet the inert premise will be supplied to the emergency premise with an enriched inert mixture instead of air.

Therefore, for JWGE operation, the second variant of expressions (5) and (6) will have the form:

$$
\begin{aligned}
& \mathrm{Q}_{\mathrm{g}}=\mathrm{Q}_{\text {sum }}+\mathrm{Q}_{\text {in }}, \\
& \mathrm{Q}_{\mathrm{i}}=\mathrm{Q}_{\mathrm{ar}}+\mathrm{Q}_{\text {out }},
\end{aligned}
$$

where $\mathrm{Q}_{\text {sum }}$ - volume flow of flue gases entering the volume of adjacent premises, $\mathrm{m}^{3} / \mathrm{s} ; \mathrm{Q}_{\mathrm{ar}}-$ volume flow of air entering the volume of the emergency premise, $\mathrm{m}^{3} / \mathrm{s} ; \mathrm{Q}_{\mathrm{in}}, \mathrm{Q}_{\text {out }}$ - volume rates of the incoming and outgoing parts of the JWGE case, $\mathrm{m}^{3} / \mathrm{s}$;

The quantities $\mathrm{Q}_{\text {in }}$ and $\mathrm{Q}_{\text {out }}$ depend only on the JWGE design productivity and in expressions (7) and (8) they will be constant, and the $\mathrm{Q}_{\mathrm{g}}$ and $\mathrm{Q}_{\mathrm{i}}$ values will depend on the intensity of the fire development in the emergency premise. In this case, the expressions (7) and (8) are valid for the time instant $\tau=0$, when $\mathrm{Q}_{\mathrm{g}}$ and $\mathrm{Q}_{\mathrm{i}}$ have the maximum value. Then, as smoke gases enter the adjacent premise, the gas exchange rate decreases with increasing temperature in this premise.

Assuming $\mathrm{Q}_{\mathrm{g}}=\max$, and $\mathrm{Q}_{\mathrm{in}}=$ const, the shielding of the flue gases of interband gas exchange between the emergency and adjacent premise with the acting JWGE in the opening is considered:

$$
\begin{gathered}
\mathrm{Q}_{\mathrm{g}}=\mathrm{Q}_{\text {sum }}-\mathrm{Q}_{\text {in }} \approx 0, \\
\mathrm{Q}_{\mathrm{i}}=\mathrm{Q}_{\mathrm{ar}}+\mathrm{Q}_{\text {out }} .
\end{gathered}
$$

So

$$
\mathrm{Q}_{\text {sum }} \approx \mathrm{Q}_{\text {in }}
$$




$$
\mathrm{Q}_{\mathrm{ar}} \approx \mathrm{Q}_{\text {out }} \text {. }
$$

The development of proposals for the structural arrangement of the implementation of the air backing method in the aperture and the theoretical justification of the JWGE operation processes in the opening of the emergency premise makes it possible to develop methods for designing ship openings using the systems of local air supply, namely:

- a technique for predicting the process of reducing the intensity of smoke entering adjacent premises when using a jet water-gas ejector;

- a technique for calculating the JWGE design parameters.

\section{Conclusions}

To achieve the research objective, a review and a critical analysis of design methods for combating the spread of smoke on ships in the event of fires are performed and their disadvantages, namely, the exit of high-temperature flue gases through an open aperture to an adjacent premise, and the creation of conditions for the failure of the ship's electrical equipment.

The regularities of the formation of an air curtain in the doors of a projected ship are determined by controlling the gas flows in the flow section. Formation of the air curtain, obtained by selecting a part of high-temperature flue gases in the JWGE case, their heat-exchange treatment and withdrawal back into the flow, is formalized. This, in turn, makes it possible to formulate conditions for the design of ship's apertures with the use of systems of JWGE-based local air supply, in which the output of high-temperature flue gases from the emergency premise of the ship will decrease without its sealing.

The obtained results substantiate the development of the method of design of ship openings using the system of local air supply that is formed by a flow of vapor-gas-water mixture directed to the emergency ship's compartment. This serves as a theoretical basis for improving the design of the ship's fire safety system using jet water ejectors in the openings of emergency premises for the purpose of shielding the thermal energy and localizing flue gases in these premises without sealing them to provide prompt access for emergency teams.

To confirm the theoretical conclusions of the study, a number of practical tests were carried out in 2012 in the volume of the research work "Development of recommendations on the use of jet water-gas ejectors for reducing gas contamination of ship spaces during a fire", "Tambur-2" cipher. Conclusions of practical tests indicate that the placement of the JWGE system in the opening of the emergency premise:

- is an effective means of reducing the intensity of smoke entering adjacent ship space;

- allows to change the motion direction of flue gases, thereby ensuring their effective shielding.

\section{References}

[1] Germanischer Lloyd. (2012). Rules for Classification and Construction. Ship Technology: Seagoing Ships. Hull Structures. Hamburg: Germanischer Lloyd SE, 390.

[2] PART IV: SOLAS CHAPTER II-2 Construction - Fire protection, fire detection and fire extinction. (2012). Canadian Supplement to the Solas Convention - TP 15211 E, 10-30. Available at: https://www. tc.gc.ca/media/documents/marinesafety/TP15211E.PDF

[3] Gatchell, W. (2003, August 1). Shipboard Firefighting: The Basics. Fire Engineering. Available at: http://www.fireengineering.com/articles/print/volume-156/issue-8/features/shipboard-firefightingthe-basics.html

[4] Morton, R. (2008, January 1). Preparing for Shipboard Fires: Firefighting Operations. FireRescue. Available at: http://www.firerescuemagazine.com/articles/print/volume-3/issue-2/firefighting-operations/preparing-for-shipboard-fires.html

[5] Tactical Ship Fire Fighting. The International Safety Training College. Available at: https:// www.istcollege.com.mt/news/course/tactical-ship-fire-fighting

[6] Water Mist Fire Protection System. Yamato Protec Corporation. Available at: http://www.yamatoprotec.co.jp/english/products/water_mist_system.html

[7] Ship fire main system. Available at: http://generalcargoship.com/fire-main.html 
[8] Wankhede, A. (2017, October 8). How High Pressure Water Mist Fire Fighting System For Ships Works? Marine Technology. Available at: https://www.marineinsight.com/tech/how-high-pressure-watermist-fire-fighting-system-for-ships-works

[9] Kuripko, O. V., Zatsarinna, T. H., Hlushkova, O. V., Pomerantsev, Ye. E., Sisin, O. O. (2008). Patent of Ukraine No. 165. Appl. No. 20041109537.

[10] Hunter, C. S. P. (2016, July 15). Marine Fire Protection: An Ungoverned Space. The Maritime Executive LLC. Available at: https:/maritime-executive.com/blog/marine-fire-protection-an-ungoverned-space

[11] Naval Vessel Fire Protection. Marioff Corporation. Available at: http://www.marioff.com/ fire-protection/fire-protection-for-marine-offshore/fire-protection-for-ships/naval-vessel-fire

[12] Cruise Ship Fire Protection. Marioff Corporation. Available at: http://www.marioff.com/ fire-protection/fire-protection-for-marine-offshore/fire-protection-for-ships/cruise-ship-fire

[13] Gianluca Zuccaro. (2012). A case of passive fire protection (pfp) in an oil gas epc project. Chemical Engineering Transactions, 26, 315-320. doi: 10.3303/CET1226053

[14] Krastelev, M. M., Myroshnychenko, S. T. Massoobmennoe ustroistvo dlia mokroi ochystky vozdukha [Mass exchange device for wet air purification]. A. s. No. 322925.

[15] Sokolov, V. V. (1998). Prystrii ochyshchennia hazopovitrianoho seredovyshcha izolovanykh prymishchen vid tverdoi fazy dymu pry pozhezhi [Device for cleaning the gas air environment of insulated premises from the solid phase of smoke during a fire]. Patent of Ukraine No. 25307 A. MPK A62V 3/00. Appl. No. 94053162.

[16] Kuripko, O. V. (2001). Sposib obiemnoho hasinnia pozhezhi i vohnestiika protypozhezhna peredilka dlia yoho realizatsii [Method of bulk extinguishing of fire and fire-resistant fire bridging for its realization]. Patent of Ukraine No. 43132 A. MPK A62S 2/00. Appl. No. 2001031466.

[17] Hrynchak, S. O. (2013) Osoblyvosti funktsionuvannia strumynnoho vodohazovoho aparatu v otvori avariinoho prymishchennia, roztashovanomu v horyzontalnomu perekrytti [Features of the operation of the jet water and gas apparatus in the opening of the emergency room, located in the horizontal overlap]. Zbirnyk naukovykh prats Akademii VMS im. P. S. Nakhimova, 4 (16), 144-154.

[18] Hrynchak, S. O. (2015). Osobennosti termogazodinamicheskikh protcessov pri rabote struinogo vodogazovogo apparata $\mathrm{v}$ poluogranichennom obeme [Features of thermogasdynamic processes during the operation of a jet water and gas apparatus in a semibounded volume]. Sudostroenie i morskaia infrastruktura, $2(4), 116-135$.

[19] Blintsov, V. S., Hrynchak, S. O. (2017). Teoretychne obgruntuvannia metodu proektuvannia korabelnykh otvoriv iz zastosuvanniam systemy pidporu povitria na osnovi strumynnoho vodohazovoho aparatu [Theoretical substantiation of the method of designing ship openings with application of the air support system on the basis of jet water and gas apparatus]. Zbirnyk naukovykh prats NUK im. admirala Makarova, 3, 10-31.

[20] Astapenko, V. M., Koshmarov, Yu. A., Pozdniakov, V. I. (1990). Mezhzonnyi gazoobmen pri pozhare $\mathrm{v}$ pomeshchenii [Interzone gas exchange in case of fire in the room]. Sistemnye issledovaniia problem pozharnoi bezopasnosti, 46-60. 